\section{Influences of Polyaromatic Hydrocarbons and Heavy Metals on a Thyroid Carcinoma Cell Line}

\author{
Jun Kobayashi, ${ }^{*, a, b}$ Ryoichi Kizu, ${ }^{c}$ \\ and Hideo Sugiyama ${ }^{b}$
}

${ }^{a}$ Laboratory Science, School of Health Science, Faculty of Medicine, Kanazawa University, 5-11-80 Kodatsuno, Kanazawa 920-0942, Japan, ${ }^{b}$ Department of Environmental Health, National Institute of Public Health, 2-3-6 Minami, Wako, Saitama 351-0197, Japan, and ${ }^{c}$ Graduate School of Natural Science \& Technology, Kanazawa University, Kakumamachi, Kanazawa 920-1192, Japan

(Received July 14, 2004; Accepted November 26, 2004; Published online December 8, 2004)

We investigated the influences (cell toxicity, endocrine disrupting action, etc.) of polyaromatic hydrocarbons (PAHs) and heavy metals on the human thyroid gland by using a cultured thyroid cancer cell (8505C). Among the six PAHs tested (anthracene, benzo $[a]$ anthracene, benzo $[a]$ pyrene, benzo $[k]-$ fluoranthene, chrysene and pyrene), anthracene did not show any effect, but cell proliferation was enhanced by benzo $[a]$ anthracene, benzo $[a]$ pyrene and benzo $[k]$ fluoranthene. Benzo[a]pyrene had an especially marked effect. On the other hand, cell toxicity was exhibited in four (cadmium, copper, nickel and zinc) of the twelve metals tested (aluminum, cadmium, calcium, copper, lead, magnesium, manganese, nickel, tin, zinc, selenate and selenite), and in particular, the influence of cadmium was remarkable. It was found that the toxicity of cadmium was decreased by the addition of high concentrations of either calcium or selenite.

Key words — thyroid, toxicity, cadmium, benzo $[a]$ pyrene, metal, polyaromatic hydrocarbon

\section{INTRODUCTION}

Environmental chemical pollutants are present in the atmosphere, water and soil, and it is known

\footnotetext{
*To whom correspondence should be addressed: Laboratory Science, School of Health Scinece, Faculty of Medicine, Kanazawa University, 5-11-80 Kodatsuno, Kanazawa 9200942, Japan. Tel.: +81-76-265-2609; Fax: +81-76-234-4369; Email: junkoba@mhs.mp.kanazawa-u.ac.jp
}

that many pollutants directly show various influences on the human body. Although it is thought that the strengths and mechanisms of pollutant actions are diverse, there are many still unknown aspects. In recent years, it has been pointed out that a few exogenous environmental pollutants have a disrupting effect on the human endocrine system (called environmental hormone action).

We previously investigated the mobilities of polyaromatic hydrocarbons (PAHs) and heavy metals in the environment. ${ }^{1)}$ Some PAHs in the atmosphere are generated by combustion of automobile exhaust gas, stoves, cigarette smoke, etc., and are taken into humans through the lungs. Some are also present in water, such as river water. ${ }^{2)}$ This presents the possibility of PAHs being taken into the body via drinking water, food, etc. Despite the increase in research on environmental hormones in recent years, including a number of reports about the influence of PAHs on the female hormone (estrogen) system ${ }^{3-5)}$ and a report about their influence on the male hormone (androgen) system, ${ }^{6}$ there are very few reports about their influence on other organs.

On the other hand, although many heavy metals cause renal insufficiency, ${ }^{7,8)}$ mercury and some other metals move to the brain and cause neurosis. ${ }^{7)} \mathrm{Al}-$ though such illnesses are considered to involve a protein such as a metallothionein and to depend on the form of metal involved, ${ }^{1,8-10)}$ details of the mechanism of toxicity are still unknown.

An epidemiological investigation conducted in Hokuriku district reported that hypertrophication and deterioration of the function of the thyroid gland occurs with high frequency in cadmium polluted areas. ${ }^{11)}$ It is well known that considerable cadmium contamination was present historically in the Jinzu river in Toyama pref., where Itai-itai disease is prevalent. However, there are almost no reports on the influence of cadmium on the thyroid gland, ${ }^{12)}$ and the mechanism by which cadmium exerts toxicity is not well understood yet. Nationwide investigation in Japan in recent years has shown that there are areas other than the Hokuriku district that have significant cadmium contamination, with cadmium being detected in the urine of many local residents (http://www.kanazawa-med.ac.jp/ pubhealt/ cadmium/cadmium.html). Moreover, in our latest investigation, it was discovered that cadmium is still detected in environmental waters in the Hokuriku district. ${ }^{13)}$ These results show that research on the pathogenesis of cadmium and mitigation of it's toxic effects is urgently required. 
In the present work, we investigated the influences of PAHs and heavy metals on the human thyroid gland by using a cultured thyroid cancer cell line.

\section{MATERIALS AND METHODS}

Cell Culture and Reagents - A cultured thyroid cancer cell (8505C) was used for all the experiments. ${ }^{14)}$ Standard PAH solutions (anthracene, benzo $[a]$ anthracene, benzo $[a]$ pyrene, benzo $[k]$ fluoranthene, chrysene and pyrene) were prepared by dissolving each commercial special grade compound in ethanol and then filtering the solution through a membrane filter (pore size: $0.45 \mu \mathrm{m}$ ). The number of living cells was counted using 3-(4,5-dimethyl-2-thiazolyl)-2,5-diphenyl-2 $\mathrm{H}$-tetrazolium bromide (MTT, Dojindo Laboratories, Kumamoto, Japan). Standard metal solutions were prepared by dissolving aluminum chloride, cadmium nitrate tetrahydrate, calcium chloride, copper (II) sulfate pentahydrate, lead nitrate, magnesium chloride hexahydrate, manganese chloride tetrahydrate, nickel sulfate hexahydrate, potassium permanganate, tin (II) chloride dihydrate, zinc chloride, sodium selenate or sodium selenite (all of special grade, Wako, Osaka, Japan) in Milli-Q water which had been autoclaved in order to sterilize it. The other reagents used were of commercially available special grade.

Procedure — RPMI-1640 culture medium (Sigma, St. Louis, MO, U.S.A.) was used for the cell cultures, with $10 \%$ fetal bovine serum (FBS, Difco, Detroit, MI, U.S.A.) and antibiotics (100 $\mu \mathrm{g} /$ $\mathrm{ml}$ streptomycin and $100 \mathrm{U} / \mathrm{ml}$ penicillin, Wako, biochemistry grade). Modified RPMI-1640 (phenol red free, Sigma) was used for all the experiments without FBS.

Cells were cultured in a $\mathrm{CO}_{2}$ incubator $\left(37^{\circ} \mathrm{C}\right.$, $5 \% \mathrm{CO}_{2}$, moistened). $8505 \mathrm{C}$ cells cultured to the subconfluent state were stripped from the laboratory dish with $0.25 \%$ trypsin/1 mM EDTA (Gibco, Carlsbad CA, U.S.A.). Medium substitution was carried out with fresh medium after centrifuging at $800 \mathrm{rpm}$ for $5 \mathrm{~min}$, and the cells were resuspended at a typical concentration $\left(5 \times 10^{4}\right.$ cells $\left./ \mathrm{ml}\right)$. One $\mathrm{ml}$ of the cell suspension was placed in each well of a 24-well plate (Iwaki Glass, Tokyo, Japan, bottom area of well $1.9 \mathrm{~cm}^{2}$ ). After standing overnight, the supernatant of the culture medium was replaced with the modified medium, and $1 \mu \mathrm{l}$ of a standard PAH solution or a standard metal solution of suitable concentration was added. After $24 \mathrm{hr}$, the numbers of living cells were counted by the MTT method.

Living Cell Counts (MTT Method) — — The MTT method performed was as follows: Supernatant was removed from all the wells of the plate prepared as explained in "Procedure" Section, so that the amount of culture medium in each well was $0.5 \mathrm{ml}$. MTT reagent ( $50 \mu \mathrm{l}, 2 \mathrm{mg} / \mathrm{ml}$ aqueous solution) was added to each well, and the mixtures were cultured in a $\mathrm{CO}_{2}$ incubator for $2 \mathrm{hr}$. The plate was then centrifuged at $2000 \mathrm{rpm}$ for $15 \mathrm{~min}$, and the residue (metabolite of MTT reagent) was dissolved in $250 \mu \mathrm{l}$ of dimethyl sulfoxide (DMSO) after complete removal of the supernatant. The relative number of living cells was determined by measuring the absorbance at $550 \mathrm{~nm}$.

Cell Culture Conditions — The cell culture conditions were examined prior to conducting the actual experiments. Dulbecco's modified Eagle's medium (DMEM)/10\% FBS and RPMI-1640/10\% FBS were previously reported as suitable for the culture medium. ${ }^{14,15)}$ Since PAHs, metals and FBS in the medium are expected to affect this experiment, the contents of these in the two media were determined as a preliminary test. We decided to use the latter medium, RPMI-1640, for the cell cultures, as it had a lower content of these substances.

As phenol red is known to have an estrogenic and chelating effect, modified RPMI-1640 (phenol red-free medium) was used for all of the experiments. Moreover, FBS contains ingredients indispensable to the growth of cells, such as amino acids. If FBS is in a culture medium at high concentration, an increase in the number of cells will be promoted and this would affect the experiments (as it would be impossible to discern effects on the reduction/increase in the number of cells). Therefore, $0 \%$ (FBS free) medium was used only during an actual experiment.

As complete cell adhesion occurred about four hours after cell scattering, the experiment was started one day afterwards by way of precaution. The number of cells and the reaction time used were $5 \times$ $10^{4}$ cells/well and one day ( $\left.24 \mathrm{hr}\right)$, respectively, taking into account the sensitivity of the MTT method, the area of cell adhesion (rate at which cells adhere and occupy the bottom of the well), and the proliferation rate. Under these conditions, it can be seen that immediately after scattering, the cells did not approach each. The time taken for cells to double by division was two to three days, and the time taken 


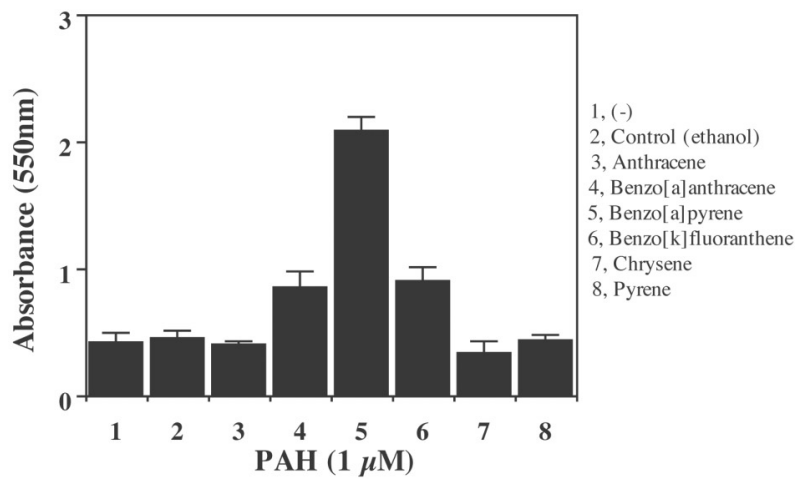

Fig. 1. Effects of $1 \mu \mathrm{M}$ PAHS on Thyroid Cancer Cell Proliferation

Data shown are means $(n=4)$. Similar data were obtained in 3 individual experiments.

for the cells to become confluent in each well was about one week (with 10\% FBS). Therefore, if a cell was not influenced by PAHs or metals, the number should not change significantly over the first $24 \mathrm{hr}$.

\section{RESULTS AND DISCUSSION}

\section{Effect of PAHs}

When $1 \mu \mathrm{M}$ of an individual PAH and the cultured thyroid cancer cells (8505C) were cultured together, cell proliferation was promoted in the presence of benzo $[a]$ anthracene, benzo $[a]$ pyrene and benzo[ $k]$ fluoranthene (Fig. 1).

It has been presumed that it is more appropriate to show cell toxicity as a decrease in the number of cells, when considering mutagenic and carcinogenic effects of these PAHs. It is very interesting that, in practice, the converse (promoting) effect was shown. The effect was also concentration dependent (Fig. 2).

Future work should use hormone receptor antagonists and agonists to further investigate the mechanism by which PAHs act as environmental hormones. Moreover, more information on PAH contents in the environment should allow more practical environmental risk assessment to be performed.

\section{Effect of Heavy Metals}

In order to obtain more information on the influences of metals present in the environment on human health, $8505 \mathrm{C}$ cells were sown in 24 -well plates, and cell proliferation and survival with each of twelve different metals (aluminum, cadmium, calcium, copper, lead, magnesium, manganese, nickel, tin, zinc, selenate and selenite) was investi-

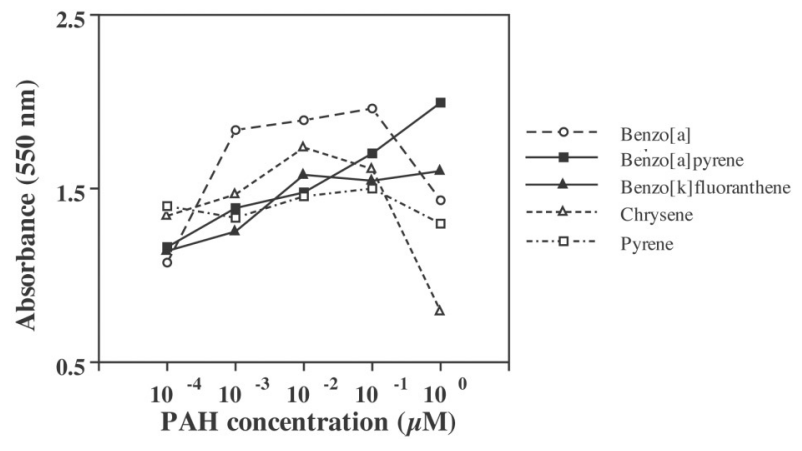

Fig. 2. Effects of PAH Concentrations on Cell Proliferation Control data: $0.657 \pm 0.107$ (A.U.); $n=4$. Similar data were obtained in 3 individual experiments.

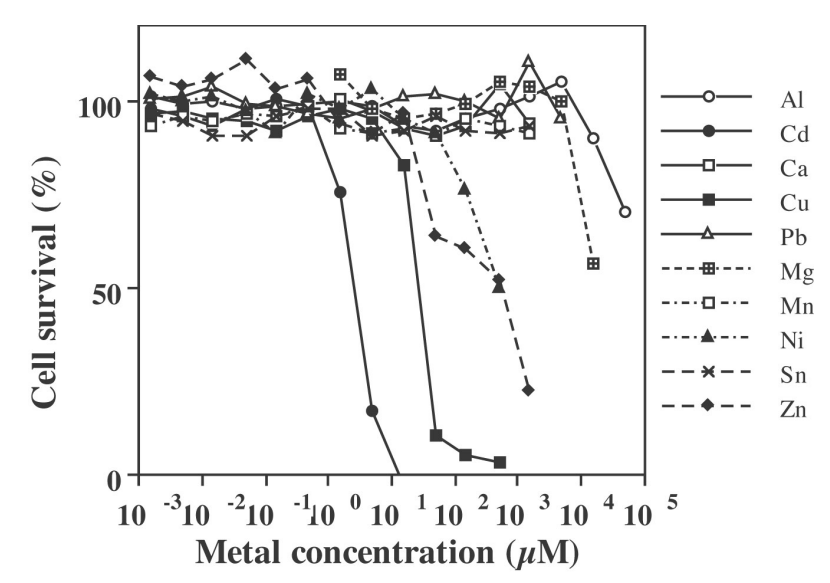

Fig. 3. Effects of Cationic Metals on Cell Survival

Data were calculated and scaled linearly using negative (only medium, $0 \%$ ) and positive (cells in medium, 100\%) controls to give the survival rate $(\%)$. When metal precipitation was observed, data were omitted and are not shown in this figure. Similar data were obtained in 3 individual experiments.

gated. For some of the metals (cadmium, copper, nickel and zinc), cell death was observed at concentrations of $1.5 \mu \mathrm{M}$ or higher (Figs. 3 and 4). As cadmium had the largest negative influence on cell survival, a more detailed investigation was performed on this metal.

When high-concentration aluminum, calcium, magnesium, lead and tin were added together with cadmium, the toxicity of cadmium was mitigated (Fig. 5). Since it is thought that anions combine with metal ions and become easy to enter in the cell, the effects of anions on cadmium toxicity were also examined. Of EDTA, acetate, citrate, selenate and selenite, only EDTA and selenite mitigated the toxicity of cadmium (Fig. 5).

Furthermore, low-concentration cadmium in the presence of aluminum, calcium, EDTA, selenate or 


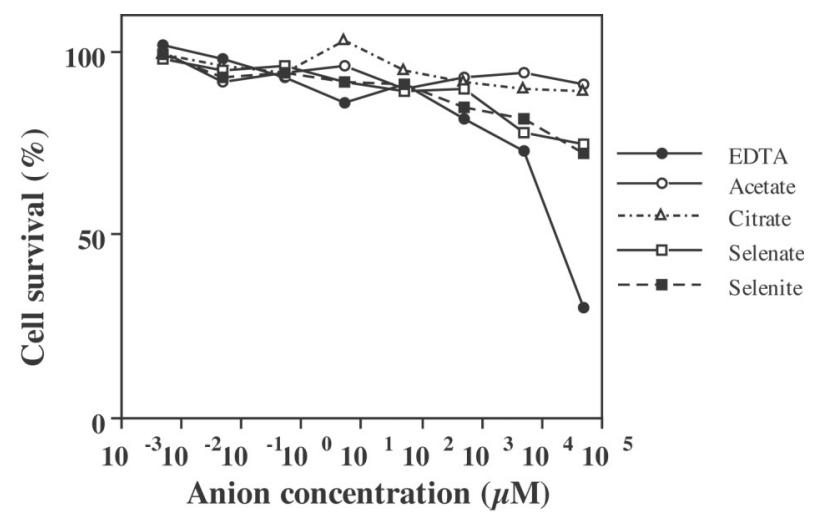

Fig. 4. Effects of Anions on Cell Survival

Data were calculated and fitted using negative and positive controls to give the survival rate (\%). Similar data were obtained in 3 individual experiments.

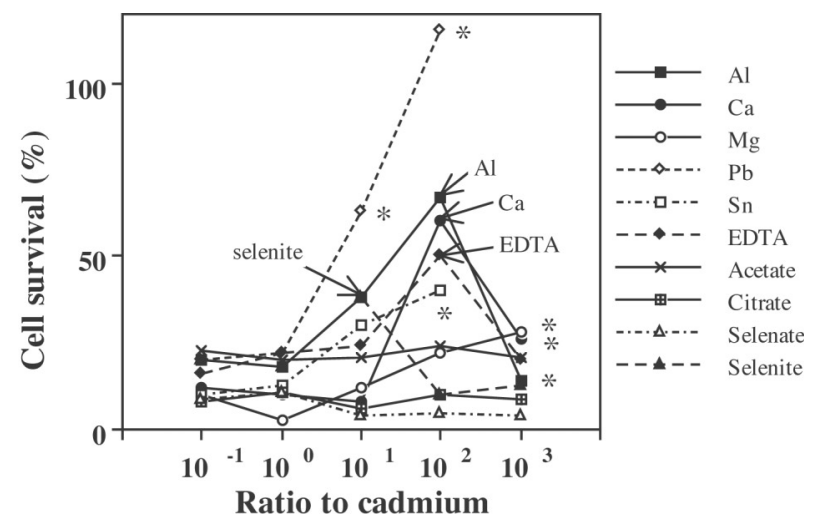

Fig. 5. Effects of Metals and Carboxylic Anions on Cadmium Toxicity to Cells

Cadnium $(3 \mu \mathrm{M})$ was added to each well, except for the controls. The concentrations of other compounds present with cadmium are shown as relative ratios to the cadmium concentration ( $\mathrm{x}$-axis). Data were calculated and fitted using negative and positive controls to give the survival rate $(\%)$. Metals other than aluminum and calcium precipitated (shown by *) at high concentrations, preventing MTT detection. High cell survival rates with no precipitation were attained using aluminum, calcium EDTA and selenite (shown by arrows). Similar data were obtained in 3 individual experiments.

selenite was investigated with respect to the amount of cadmium being taken into cells and supernatant. When present with aluminum, cadmium disappeared from both the supernatant and the cell. When present with EDTA, cadmium was present only in the supernatant, largely at the concentration added. When calcium, selenate or selenite was present with cadmium, cadmium was found in both the supernatant and the cells. When cadmium and selenate were both present, the concentration of cadmium in the supernatant and the cells was almost the same as when no selenate was added, but in the presence of calcium

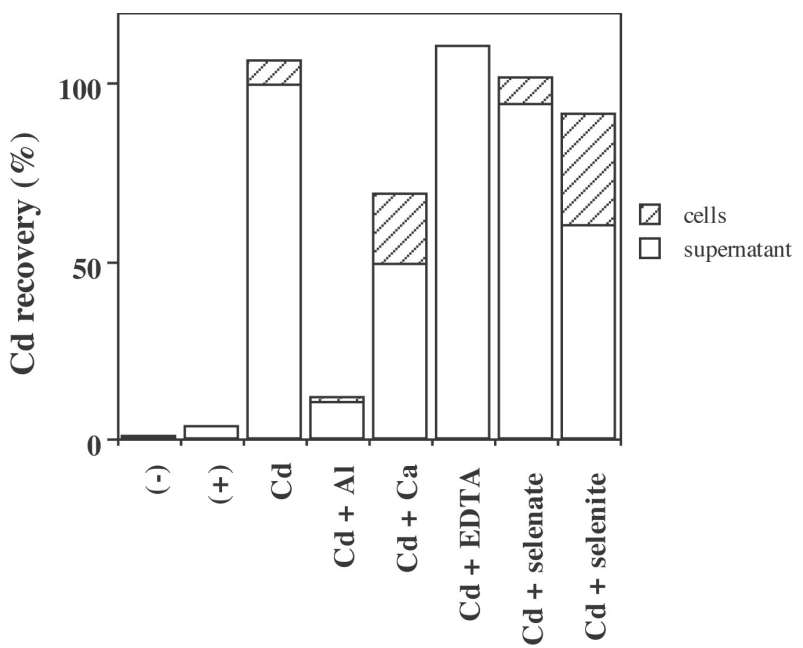

Fig. 6. Cadmium Recovery from the Supernatant Medium and the Cells

Cadmium $(1 \mu \mathrm{M})$ was added. The concentrations of coexisting compounds were $10 \mu \mathrm{M}$ (selenate and selenite) or $100 \mu \mathrm{M}$ (aluminum, calcium and EDTA), based on the results presented in Fig. 5 (arrows). $(-)$ : medium only; (+): cells + medium; Cd: cadmium + cells + medium. Similar data were obtained in 3 individual experiments.

and selenite, the cadmium concentration in the supernatant was lower, and that in the cells was higher (Fig. 6).

These results showed that although cadmium developed cell toxicity on being taken into a cell, this toxicity was weakened on accumulation in cells, probably as a result of a change in the chemical form of the cadmium. It is thought that cadmium toxicity was mitigated in these experiments because cadmium was unable to act on the cells due to co-precipitation with the hydroxides of aluminum, lead and tin (the precipitation of lead and tin was seen visually). EDTA is considered to block cadmium invasion of cells by a chelate effect. However, there are some reports that cadmium blocks calcium metabolism, and it is thought that cells have a site where cadmium and calcium bind competitively. ${ }^{16)} \mathrm{Al}$ though selenium shows toxicity independently, it has also been reported that it works as an antidote to cadmium.

In the present experiments, even when calcium was present at high concentrations, cell toxicity by calcium itself was not shown, only a mitigation of the toxic effect of cadmium was exhibited. Toxicity was mitigated more weakly by selenite, and selenite itself exhibited weak toxicity. From these results, it is postulated that the mechanisms by which they act as antidotes differ.

Future work should address why the detoxifica- 
tion action of cadmium which was seen with selenite was not seen with selenate, and the mechanism of cadmium toxicity and how calcium and selenite mitigate this.

Acknowledgements This research was performed with the assistance of an area-studies grant-in-aid (2000) from Kanazawa city. We are thankful to the Cell Resonance Center for Biomedical Research of Tohoku University for supplying a cultured thyroid carcinoma cell (8505C), and Prof. Kazuichi Hayakawa, Kanazawa University Pharmacy Department for helpful discussions.

\section{REFERENCES}

1) Kobayashi, J. and Miyazaki, M. (1995) Determination of aluminum in tap water and environmental waters by flow injection analysis. Hokuriku J. Public Health, 21, 51-55.

2) La Rocca, C., Conti, L., Crebelli, R., Crochi, B., Iacovella, N., Rodriguez, F., Turrio-Baldassarri, L. and di Domenico, A. (1996) PAH content and mutagenicity of marine sediments from the Venice lagoon. Ecotoxicol. Environ. Saf., 33, 236-245.

3) Arcaro, K. F., O'Keefe, P. W., Yang, Y., Clayton, W. and Gierthy, J. F. (1999) Antiestrogenicity of environmental polycyclic aromatic hydrocarbons in human breast cancer cells. Toxicology, 133, 115-127.

4) Arcaro, K. F., Yang, Y. and Gierthy, J. F. (1999) Benzo[k]fluoranthene enhancement and suppression of 17beta-estradiol catabolism in MCF-7 breast cancer cells. J. Toxicol. Environ. Health, 58, 413-426.

5) Charles, G. D., Bartels, M. J., Zacharewski, T. R., Gollapudi, B. B., Freshour, N. L. and Carney, E. W. (2000) Activity of benzo[a]pyrene and its hydroxylated metabolites in an estrogen receptor-alpha reporter gene assay. Toxicol. Sci., 55, 320-326.

6) Kizu, R., Ishii, K., Kobayashi, J., Hashimoto, T., Koh, E., Namiki, M. and Hayakawa, K. (2000) Antiandrogenic effect of crude extract of C-heavy oil. Material Science \& Engineering C, 12, 97-102.

7) Wada, O. (1985) Kinzoku to hito -Ecotoxicology to rinsho (metal elements and human beings; with emphasis of clinical ecotoxicology in Japanese), Asakura Shoten, Tokyo.

8) Ishido, M. and Kunimoto, M. (2001) Regulation of cell fate by cadmium and Zinc. J. Health Sci., 47, 9-13.

9) Hogstrand, C., Lithner, G. and Haux, C. (1991) The importance of metallothionein for the accumulation of copper, zinc and cadmium in environmentally exposed perch, Perca fluviatilis. Pharmacol. Toxicol., 68, 492-501.

10) Kondoh, M., Ogasawara, S., Aragaki, S., Higashimoto, M. and Sato, M. (2001) Cytochrome $\mathrm{C}$ release from mitochondria induced by cadmium. J. Health Sci., 47, 78-82.

11) Nishijo, M., Nakagawa, H., Morikawa, Y., Tabata, M., Senma, M., Miura, K., Tsuritani, I., Honda, R., Kido, T., Teranishi, H. and Kawano, S. (1994) A study of thyroid hormone levels of inhabitants of the cadmium-polluted Kakehashi river basin. Jpn. J. Hyg., 49, 598-605.

12) Yoshizuka, M., Mori, N., Hamasaki, K., Tanaka, I., Yokoyama, M., Hara, K., Doi, Y., Umezu, Y., Araki, H. and Sakamoto, Y. (1991) Cadmium toxicity in the thyroid gland of pregnant rats. Exp. Mol. Pathol., 55, 97-104.

13) Kobayashi, J. and Kizu, R. (2001) Evaluation of the metal contents in river water using a simple fractionation method. J. Health Sci., 47, 460-463.

14) Ito, T., Seyama, T., Hayashi, Y., Hayashi, T., Dohi, K., Mizuno, T., Iwamoto, S. K., Tsuyama, N., Nakamura, N. and Akiyama, M. (1994) Establishment of two human thyroid carcinoma cell lines (8305C, 8505C) bearing p53 gene mutation. Int. J. Oncology, 4, 583-586.

15) Smanik, A. P., Fithian, J. L. and Jhiang, M. S. (1994) Thyroid peroxidase expression and DNA polymorphisms in thyroid cancer. Biophysical Res. Commun., 198, 948-954.

16) Tateno, M. (1971) Fundamental research on cadmium poisoning (the 3 rd report) - the state of the thyroid gland at the time of cadmium poisoning, and influence of vitamin $\mathrm{E}$ exerted on it - Hormone To Rinsho, 19, 719-721. 